\title{
On the seismic response of instable rock slopes based on ambient vibration recordings
}

\author{
Ulrike Kleinbrod $^{1 *}$ (D), Jan Burjánek ${ }^{2}$ and Donat Fäh ${ }^{1}$
}

\begin{abstract}
Rock slope failures can lead to huge human and economic loss depending on their size and exact location. Reasonable hazard mitigation requires thorough understanding of the underlying slope driving mechanisms and its rock mass properties. Measurements of seismic ambient vibrations could improve the characterization and detection of rock instabilities since there is a link between seismic response and internal structure of the unstable rock mass. An unstable slope near the village Gondo has been investigated. The unstable part shows strongly amplified ground motion with respect to the stable part of the rock slope. The amplification values reach maximum factors of 70 . The seismic response on the instable part is highly directional and polarized. Re-measurements have been taken 1 year later showing exactly the same results as the original measurements. Neither the amplified frequencies nor the amplification values have changed. Therefore, ambient vibration measurements are repeatable and stay the same, if the rock mass has not undergone any significant change in structure or volume, respectively. Additionally, four new points have been measured during the re-measuring campaign in order to better map the border of the instability.
\end{abstract}

Keywords: Ambient vibrations, Instable rock slopes, Site amplification

\section{Introduction}

Recently, several ambient noise measurements have been taken in Switzerland in order to study the seismic response of potential rockslides concerning a broad class of slope failure mechanisms, material conditions, tectonic settings and activity levels. The site selection was performed with support of the Swiss Federal Road Office (ASTRA) and Swiss Federal Railways (SBB) to spot specific high-risk locations for the transport networks. So far, the seismic responses of 25 different rock slope instabilities have been investigated. Additional sites in Switzerland have been analyzed by Fäh et al. (2012). Each site delivers quite specific seismic signatures representing the rock slope properties and hardly allows a direct integration of data from different sites. An overview focused on the information that can be obtained from ambient noise analysis for the characterization of slope stability, and slope dynamic response during earthquakes is given in the paper by Del Gaudio et al. (2014).

\footnotetext{
*Correspondence: ulrike.kleinbrod@sed.ethz.ch

1 Swiss Seismological Service, ETH Zürich, Zurich, Switzerland Full list of author information is available at the end of the article
}

In this paper, we present the site Gondo in Valais (Fig. 1a) which showed the highest amplification (factor 70) among all the investigated sites. The instable part of the rock slope comprises around $4000 \mathrm{~m}^{3}$ of rock. In Fig. 1b, one can see a gallery and a street on the foot of the rock slope that will be affected in case of a slope failure.

\section{Methods}

The site response analysis presented here has been based on ambient vibration observations. The recording time for all measurements was $90 \mathrm{~min}$, and the data acquisition was done with a digital recording unit coupled to Lennartz 3D seismometer with an eigenperiod of $1 \mathrm{~s}$. The frequency band of interest lies only up to $20 \mathrm{~Hz}$ considering the minimum scales (wavelengths) of interest on the order of $10-50 \mathrm{~m}$. This estimate originates from an empirical observation that the response usually becomes highly variable for frequencies above $20 \mathrm{~Hz}$ for an interstation distance of this order (tens of meters). It was observed in the past that the seismic response is sensitive to the meteorological conditions, especially during freezing periods (Bottelin et al. 2013; Burjánek et al. 2017). 


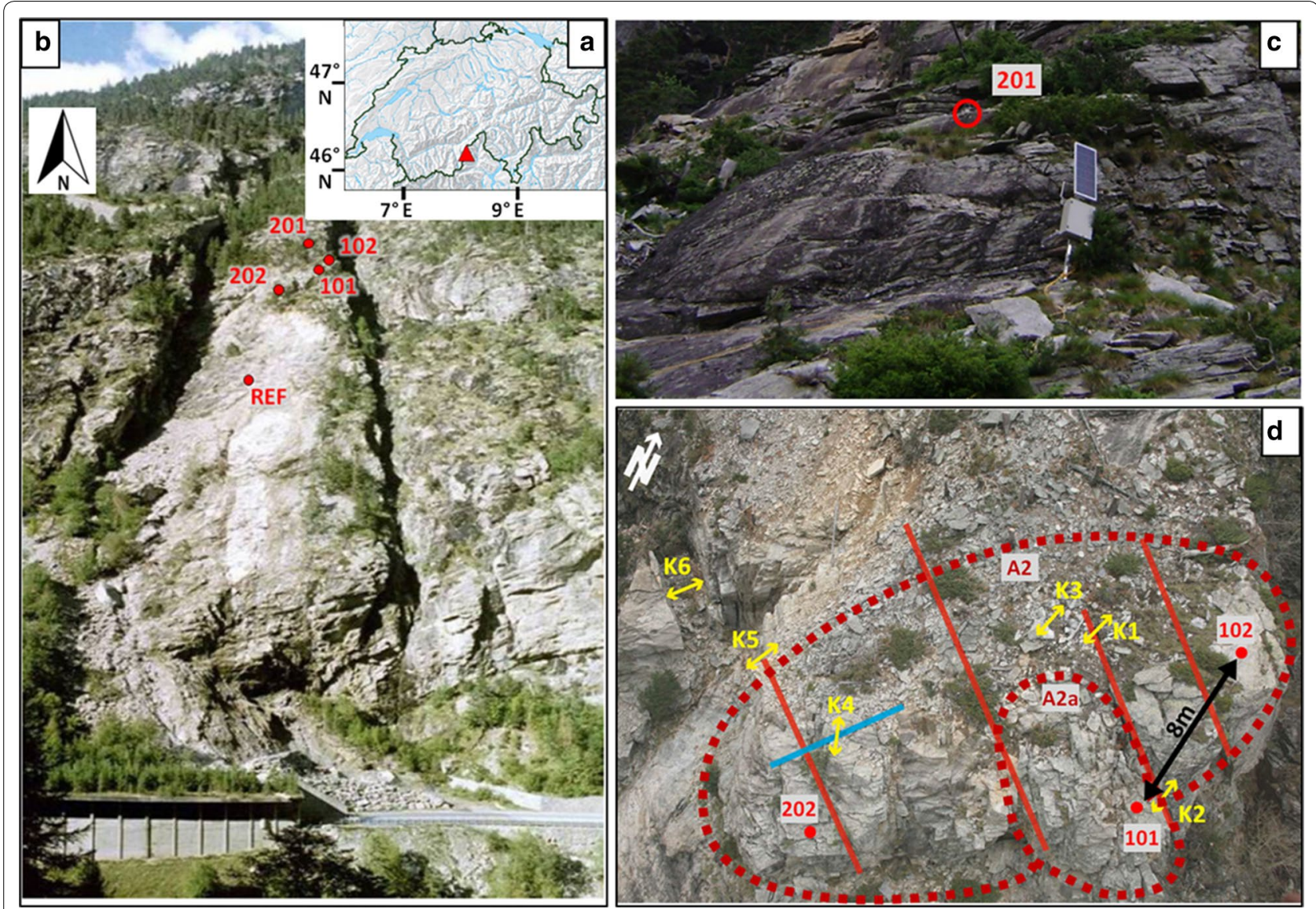

Fig. 1 a Location of the site Gondo in Switzerland. $\mathbf{b}$ Overview of the whole rock slope with the measuring configuration (view to the North from the opposite valley flank); red dots are representing the measuring points including the reference station (GON101=101, etc.). c Detailed view of measuring point 201. d Aerial photograph taken from the helicopter showing the stations 101, 102 and 202. The red dotted lines divide the instability in the different risk potentials A2 and A2a. The yellow arrows represent the crack meters. The blue and red lines indicate the cracks. The distance from points 101 to 102 is around $8 \mathrm{~m}$

However, in general, the measurements presented here took place during dry, non-freezing periods without rainfall. Therefore, the effect of water saturation and ambient temperature is mostly neglected in the data interpretation. It is assumed that the water level is low at the investigated sites due to the fast water runoff at rock slopes.

The recordings of the seismic ambient vibrations have been analyzed with the time-frequency-dependent polarization analysis (TFPA) proposed by Burjánek et al. (2010) and site-to-reference spectral ratios (SRSR). TFPA characterizes the movement of the ground particles for each time step and frequency by an ellipse, which is described by three parameters, the ellipticity, the strike and the dip. The ellipticity is the ratio between the lengths of semiminor and semimajor axis and describes the shape of the ellipse. A value of 1 means circular, whereas values close to 0 linear movement, respectively. Values between 0.3 and 0.4 can be considered as "normal" or standard for hard rock sites (values observed on average for uncorrelated components of ground motion). The strike gives the orientation of the semimajor axis with respect to North. The dip shows how much the plane of the ellipse is tilted with respect to the horizontal plane. More technical details about the method are described in the paper by Burjánek et al. (2012). As an example, the output of the polarization analysis for the reference station at the site Gondo is shown in Fig. 2.

The second method is the site-to-reference spectral ratios (SRSR). In particular, the recorded time series are split into non-overlapping time windows $(\sim 100 \mathrm{~s})$. As a next step, for each time window the Fourier amplitude power spectrum is estimated by a multi-taper method developed by Prieto et al. (2009) and normalized by the corresponding spectrum of the reference station. Then, the geometrical mean of the horizontal components of all windows is compiled. This procedure can be applied for any horizontal direction. In particular, the direction of the main polarization is of interest as maximum 


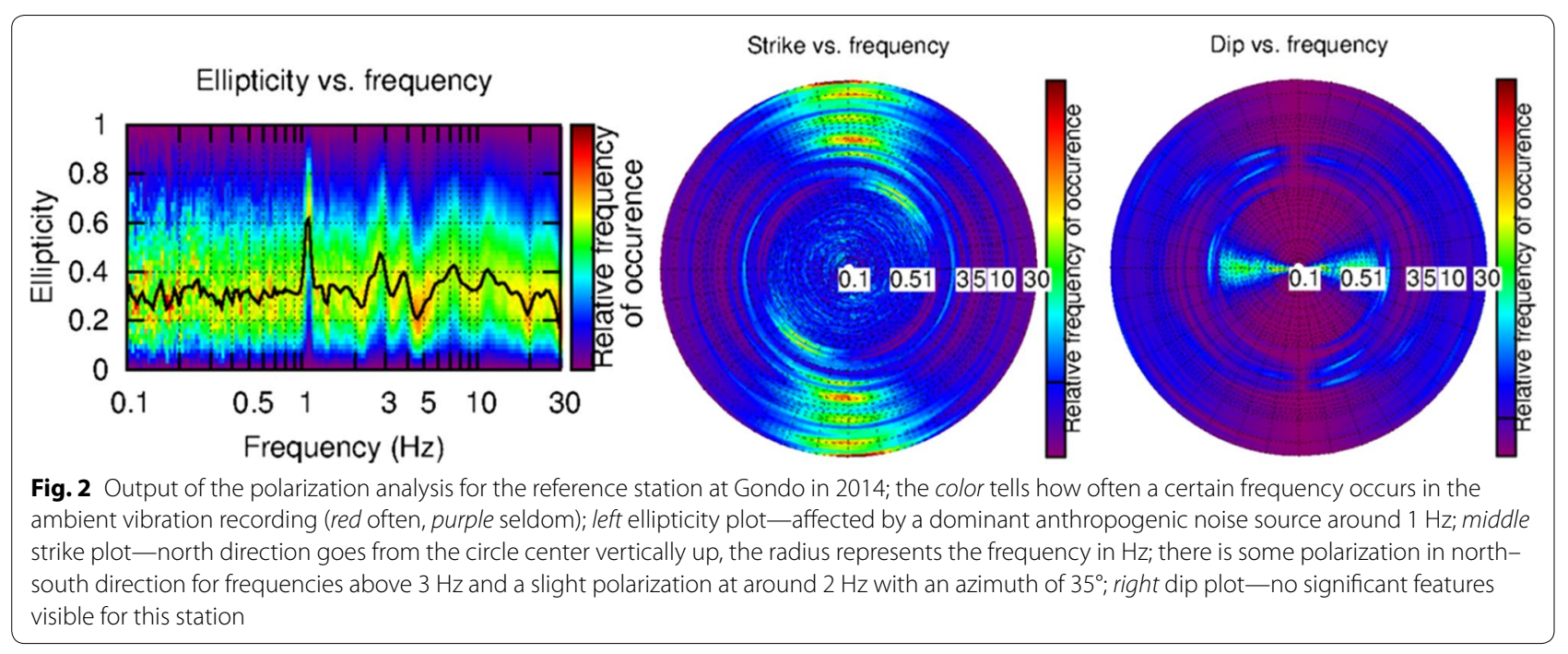

amplifications were usually observed in this direction. The output of the SRSR is a frequency-dependent amplification function with respect to the reference station, which can be used to identify fundamental frequencies of the whole instability as well as other resonance frequencies caused by local geological features. Very narrow peaks in the spectra (i.e., almost harmonic signals) are typically interpreted to be caused by dominant anthropogenic sources (see peaks between 1 and $2 \mathrm{~Hz}$, for example, in Fig. 5).

The goal of SRSR is to eliminate source- and pathspecific effects so that only site signatures remain which are related to the instable rock mass. In particular, the local amplification factors are considered when judging whether a given rock mass is potentially instable or not with respect to the presumably stable, reference conditions. The relative amplification value indicates how much the rock mass is free to vibrate. For amplification factors around 4, rock slopes are already considered as considerably weakened (and potentially instable), while factor 8 or above represent heavily disturbed rock associated with unstable slopes. Amplification factors up to 70 have been observed in the dataset consisting out of 25 sites. Such extreme amplifications might result in a slope failure in case of an earthquake. Exceptional cases are rock columns or rock masses with a tower-like geometry. In particular, such objects are often highly amplified and show clear signatures in the polarization analysis as well (Kleinbrod et al. 2017). Nevertheless, a towershaped rock might be still stable since the amplification of ground motion could result just from the extreme geometry. In the same way, high-rise buildings show high amplification at top floors (i.e., low damping ratio) at the eigenfrequencies (e.g., Arakawa and Yamamoto 2004).

\section{Results and discussion}

Two sets of measurements have been taken at the site Gondo: the first one in June 2014, while the second one a year later in June 2015. For each of the measurement campaigns, the reference station was installed below the instable part (see Fig. 1b). The reference station for the 2015 campaign was not exactly at the same location as in 2014, but within a distance of 15 meters from the original one. The configuration of the 2014 measurement is shown in Fig. 1b. The points GON101, GON102 and GON201 were re-measured in 2015, while four additional points were investigated in order to better map the border between instable and stable parts. The instable part could be divided into two different compartments A2 and A2a (Fig. 1d), which are assigned with a different level of risk by engineering geologists. For the smaller and more fractured volume A2a the probability of rock falls (with smaller rock blocks of about 1 cubic meter) is higher than for the volume A2. The area A2 rather generates rock failures with bigger rock blocks of $5-20 \mathrm{~m}^{3}$, but the likelihood for the occurrence of such a scenario is lower (ASTRA Los 13, 2012). The exact depth of the instability is still unknown (personal communication with the responsible geologists).

In order to permanently monitor the rock slope, some crack meters have been installed by ASTRA. The data from crack meters show recent kinematic activity of the slope. The crack meters K1 and K2 (Fig. 1d)-which are monitoring a big crack in the eastern part of the instability between the stations GON101 and GON102-show seasonal variations of 1.5 , respectively, $2 \mathrm{~mm}$. Such seasonal variations can be explained by the temperaturedependent material expansion of rock. The effective measuring displacement between November 2013 and 
November 2014 was $0 \mathrm{~mm}$ for the crack meter K1 and $1.5 \mathrm{~mm}$ for K2. Crack meter K3 (westward to K1) monitors a crack covered with loose rocks and shows seasonal variations of only $0.2 \mathrm{~mm}$ (effective measuring displacement of $0.4 \mathrm{~mm}$ ). In addition, crack meter $\mathrm{K} 4$ above the station GON202 monitors a single block with seasonal variations of $0.4 \mathrm{~mm}$ and effective displacements of $0.7 \mathrm{~mm}$ (ASTRA 2014).

Considering the seismic data, all the stations (including the reference station) show a narrow, steep peak at around $1 \mathrm{~Hz}$ in the power spectra. Although the frequency of this peak coincides with the eigenperiod of the seismometer, they are not related. The instrument was working properly, as tested at other sites. The exact origin of this peak is not known, but it is likely caused by a dominant anthropogenic source. Since it is not related to the site response, it will not be discussed further.

GON101 shows polarized ground motion over a broad frequency range $(6-20 \mathrm{~Hz})$ (Fig. 3). This indicates stronger fracturing of the rock mass at a range of scales, so that resonance does not occur in a narrow frequency band. This is supported by geological observations of a dense network of cracks (Fig. 1d, parallel, red lines indicate the main joint set) as well as higher displacements from crack meter $\mathrm{K} 2$, what would indicate a freedom of movement. GON102 shows similar ellipticity values as GON101, but the range of affected frequencies is narrower $(8-15 \mathrm{~Hz})$. The station GON102 is located in an area with less visible, superficial fractures (Fig. 1d), which could explain the more restricted frequency band. In particular, the resonance would be attributed to a bigger rock block $\left(\sim 3000 \mathrm{~m}^{3}\right)$. Station GON202 is located slightly below and 15 , respectively, $20 \mathrm{~m}$ westward from GON101 and GON102 and shows strongly polarized ground motion in north-south direction for frequencies between 3.5 and $18 \mathrm{~Hz}$ (Figs. 3, 4). The north-south polarization of station GON202 might result from overlapping cracks. In the proximity of stations GON202, one crack is running in the direction $30^{\circ}$ from north (indicated by a blue line in Fig. $1 \mathrm{~d}$ and monitored by crack meter $\mathrm{K} 4$ ) and one in the direction $120^{\circ}$ from north (most left red line in Fig. 1d). The sensor GON201 is installed slightly above GON102. The resonating frequencies are restricted to $8-10 \mathrm{~Hz}$, and the rock mass seems to be less fractured in the field, which could indicate an internal compact, but unstable volume. The stations GON101, GON102 and GON202 show a very similar pattern in the ellipticity plot, so that they are likely installed on the same compartment of the instable rock slope. The only difference originates in near-surface structures. Furthermore, GON202 shows also in lower frequencies (between 4 and $6 \mathrm{~Hz}$ ) very
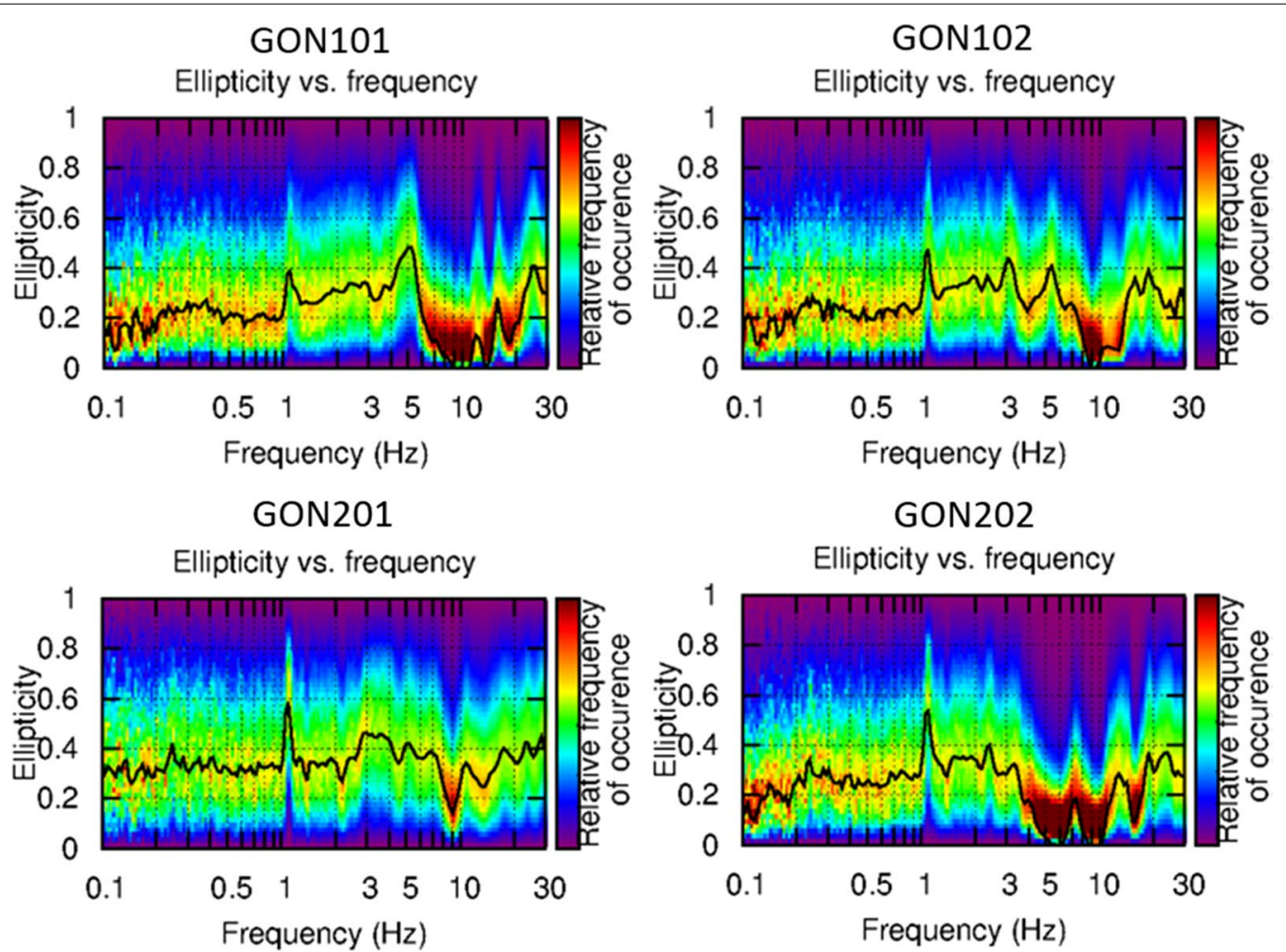

Fig. 3 Ellipticity plot-indicating frequencies with directional ground motion 


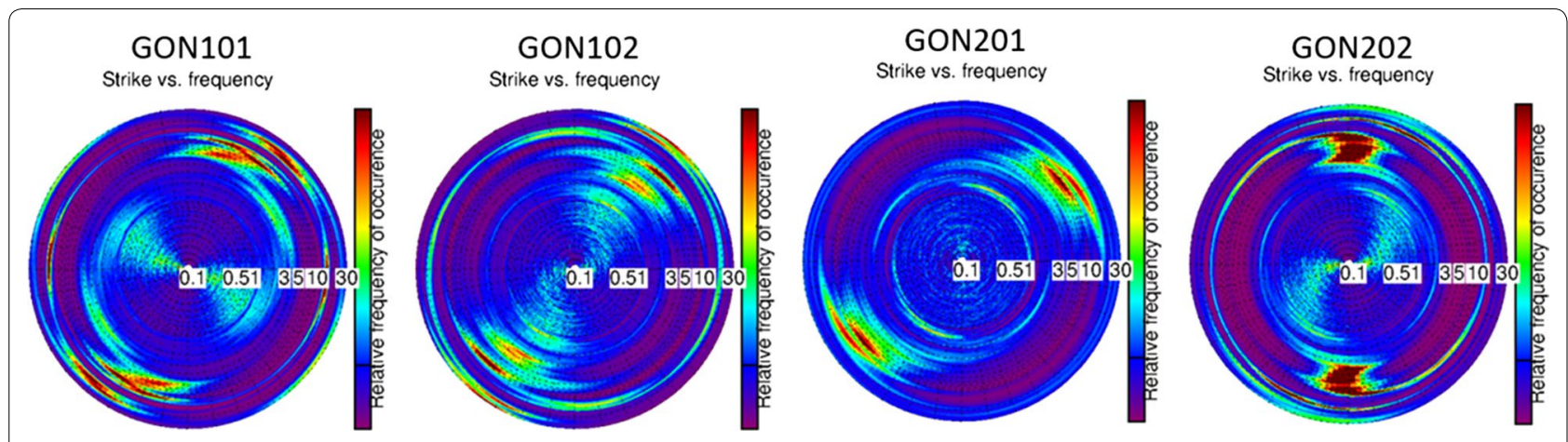

Fig. 4 Strike plot-azimuth of the polarized ground motion
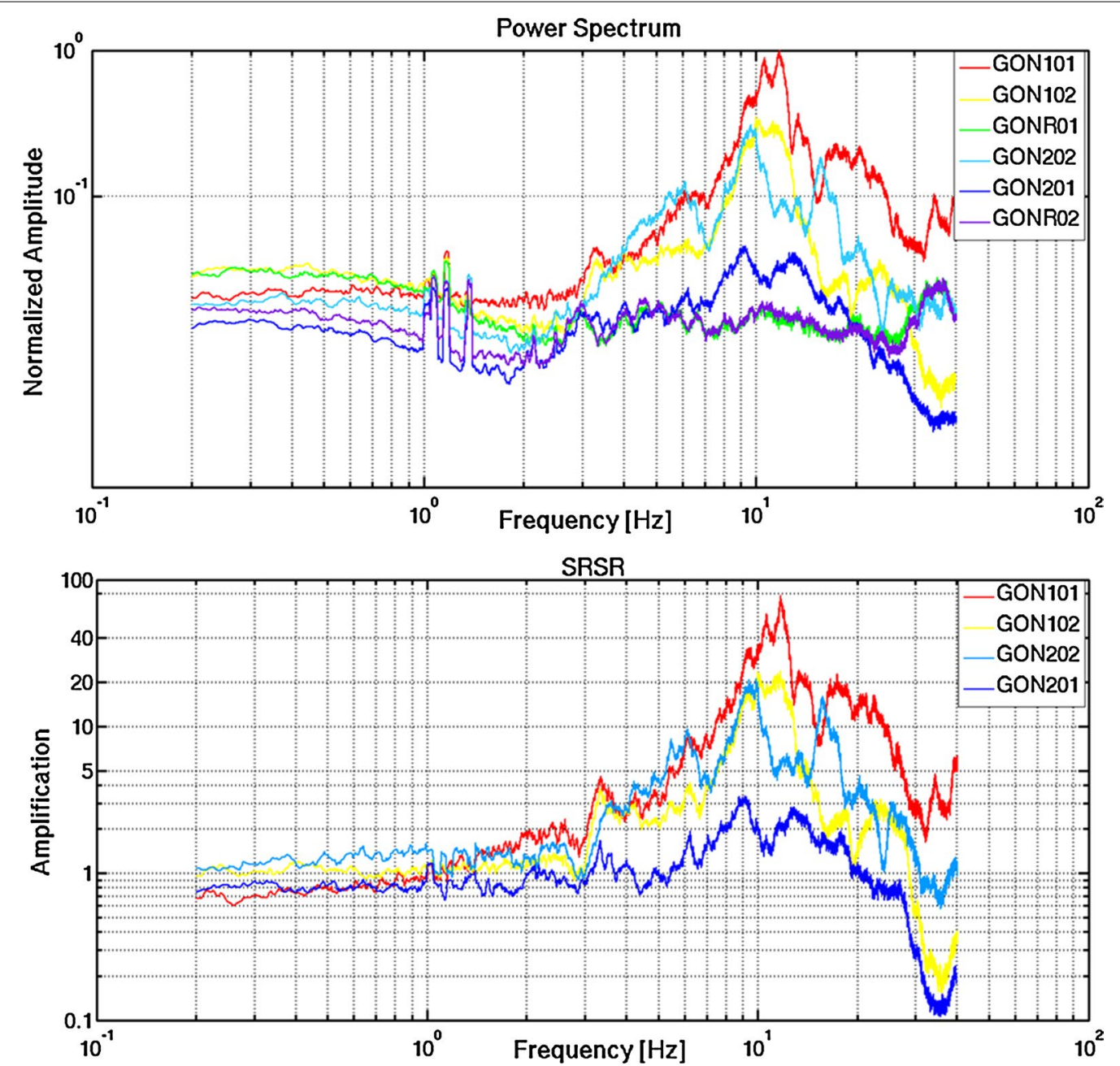

Fig. 5 Absolute power spectrum (upper plot) and SRSR (lower plot) from June 2014 in the direction $40^{\circ}$ from north

directional ground motion. In comparison, GON201 seems to approach the border of the instability toward the stable part as it is not as strongly affected as the other stations. However, it shows the typical features of a detached single block (e.g., well-defined eigenfrequency, clear polarization). 
The strike plot is shown in Fig. 4. While comparing the different stations with each other, it gets obvious that GON101, GON102 and GON201 are similar, but the azimuth of the polarization direction is slightly changing. GON201 is the most upper station (within the sliding area) with a polarization azimuth of around $50^{\circ}$, GON102 around $40^{\circ}$ and GON101 around $20-30^{\circ}$. The main direction of ground motion polarization is usually parallel to the slope deformation (e.g., Burjánek et al. 2010, 2017). Therefore, the slightly rotating strike angle could indicate that the rock-slide movement is not linear in the area of the three stations, but contains a rotation. Stations GON202 (Fig. 4) and GONREF (Fig. 2) show both northsouth polarized ground motion.

In Fig. 5, the geometric mean of the power spectrum of the horizontal components (upper plot) and the siteto-reference spectral ratios (lower plot) is shown. In this plot, the anthropogenic peaks around $1 \mathrm{~Hz}$ get clearly visible. The reference station was recording this anthropogenic noise as well, and by calculating the spectral ratios, these peaks can be eliminated. An increase in the power spectrum can be recognized at $3.5 \mathrm{~Hz}$ as well as $6 \mathrm{~Hz}$.

The first peak in amplification around $3.5 \mathrm{~Hz}$ reaches factors around 5 at the stations GON101 and GON102 and can be seen as well at the stations GON202 (Fig. 5) and GON105 (see Figs. 7, 8), while the other installed stations do not show this feature. Since the frequency of this peak is relatively low $(3.5 \mathrm{~Hz})$, it is likely related to a deeper but laterally limited structure. A potential border of such structure is indicated by a dashed orange line in Fig. 7 (based just on our seismic recordings). The highest amplification is reached at around $10 \mathrm{~Hz}$. This frequency is considered to be the resonance frequency of the semi-isolated rock mass A2 (Fig. 1d). The amplification reaches a factor over 60 at station GON101 and about 20 for stations GON102 and GON202, respectively, which indicates highly instable conditions (structure is almost free to vibrate). In particular, since the rock mass does not have a tower-like shape, the internal rock mass has to be significantly weakened, in order to produce such high amplifications. Besides the stable reference station, the point GON201 can be regarded as less critical (but the amplification factor of 4 at about $9 \mathrm{~Hz}$ is still significant) and not part of the instable part A2.

Measurements at the site Gondo have been taken in June 2014 and 1 year later in June 2015 in order to see whether the dynamic behavior of the instability has changed. In 2015, only GON101, GON102 and GON201 have been re-measured. In Fig. 6, the SRSR curves from 2014 (labeled with GON1-...) and 2015 (labeled with GON2-...) are plotted together. One can see that the dynamic behavior did not significantly change, and the measurements with 1-year time gap correspond very well

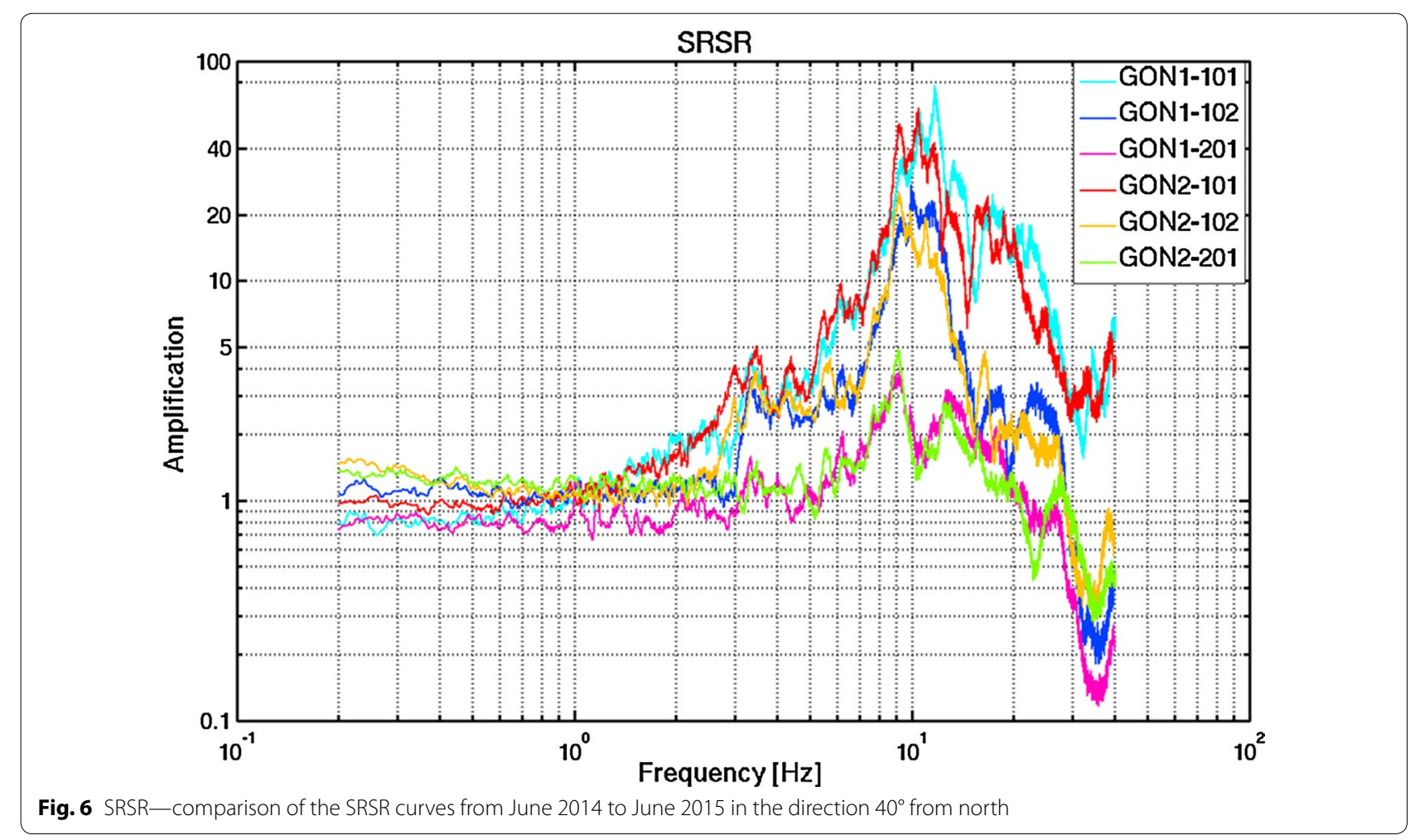


to each other. The measurement of the extreme amplifications was reproduced and cannot be considered as a random fluctuation. Although the response can vary with temperature (Bottelin et al. 2013; Burjánek et al. 2017), the re-measurement in 2015 was taken in very similar meteorological conditions as in 2014. The seismic activity was particularly low in the vicinity of the site in between June 2014 and June 2015 (no events of $M>2$ within an epicentral distance of $20 \mathrm{~km}$, no events of $M>3$ within an epicentral distance of $60 \mathrm{~km}$ ). A longer continuous seismic measurement is required to identify potential changes in the response due to weather conditions or earthquakes.

The lower and western border of the instability A2 with a resonance frequency of around $9-10 \mathrm{~Hz}$ can be clearly determined by a step (of a few meters) in the topography, while the eastern border is given by a ravine (Fig. 1d). In contrast, the upper border is not obvious. It is hard to find any geomorphological feature (like scarp, back scarp, prominent crack) that would delineate the instable volume, as the area is covered by rock deposits. During the 2015 measuring campaign, the seismic ambient vibrations were recorded at four additional points installed slope upwards (see Fig. 7points GON104, GON105, GON106 and GON108) in order to see whether the instability A2 stretches above the slightly amplified station GON103. While looking at Fig. 8, one can see that the SRSR curves of GON103 and GON104 are identical and have a maximum amplification factor of 5 at $9 \mathrm{~Hz}$, while the stations 106 and 108 show only amplifications of factors between 1 and 2 over the whole frequency band of interest (between 1 and $15 \mathrm{~Hz}$ ). Thus, the upper border of the instability is reached in the area of the stations 103 and 104. The assumed upper border of the instability A2 is indicated by the blue dashed line in Fig. 7. When looking at station 105 , one can see a highly amplified peak (factor 40) at $20 \mathrm{~Hz}$. This strong amplification is caused likely by the completely loose surface material as the station is installed on a talus and not related to any deeper structure of the rock slope.

\section{Conclusions and outlook}

Ambient vibrations allow for a rapid detection and objective characterization of potential rock slope instabilities. It is possible to distinguish unstable areas, slope eigenfrequencies, local amplification levels (due to weak excitation) and local deformation directions.

As the example of Gondo has shown here, the recordings of ambient vibrations are stable over years in dry periods. This observation has been confirmed as well by a permanent station installed at the site Preonzo (Burjánek et al. 2017). Therefore, ambient vibrations provide

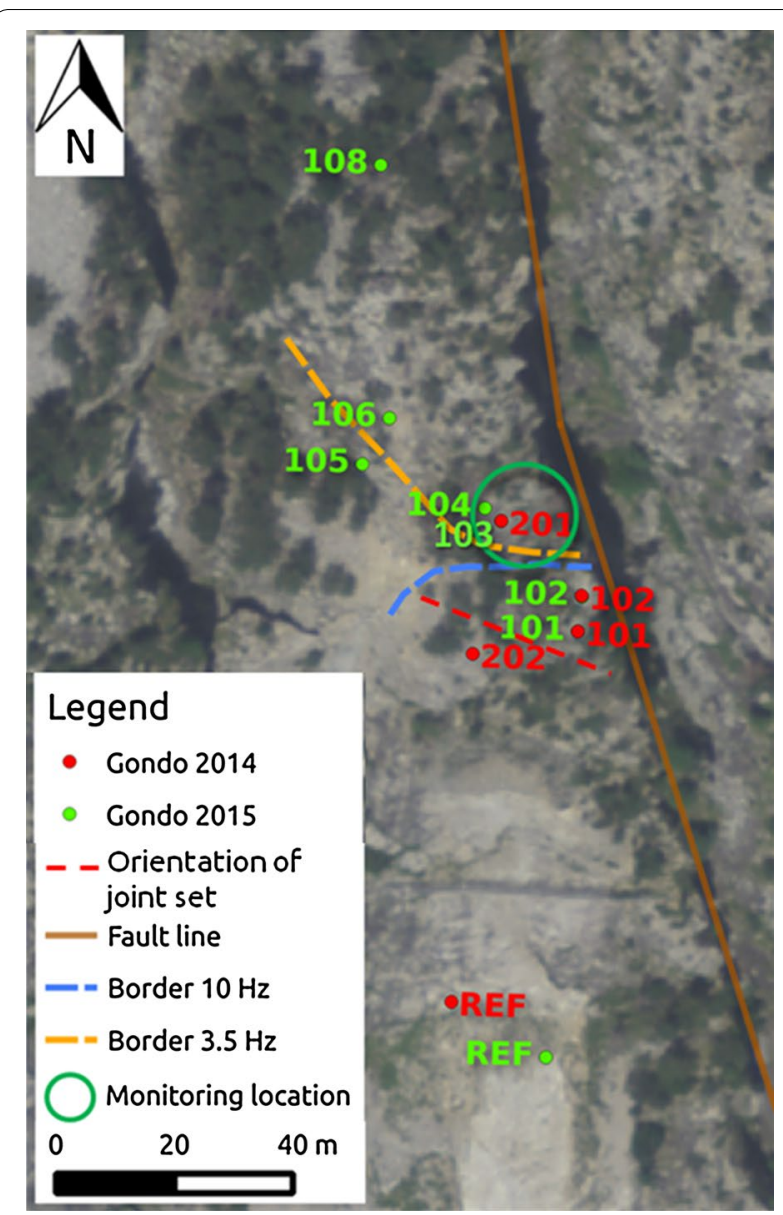

Fig. 7 Overview of the measuring configuration for the measurements in 2014 (red) and 2015 (green). The red dashed line shows the orientation of the main joint set (red lines in Fig. 1d). The brown line indicates a fault line (swisstopo), the green circle shows a potential, relevant location for permanent monitoring, the orange dashed line represents the assumed border of the deep seated instability $(3.5 \mathrm{~Hz}$ peak) and the blue dashed line represents the border of the instability A2 $(10 \mathrm{~Hz}$ peak). As the coordinates of the sensors were only measured by GPS with an accuracy of around $5 \mathrm{~m}$, the sensor locations can contain errors

a robust estimate on the dynamic behavior of the rock mass itself. The seismic response does not change without any significant impact on the rock mass and its internal structure.

Extreme amplifications identified at the Gondo site (factors of 70) present an absolutely unique observation, especially considering the rock outcrops at the site. We are not aware of any other rock site presenting so high amplification levels. However, since comparable amplification levels (factors of 35) were previously observed at another rock slope instability (Preonzo, Burjánek et al. 2017), we suggest that this phenomenon might be not rare for instabilities close to collapse. 


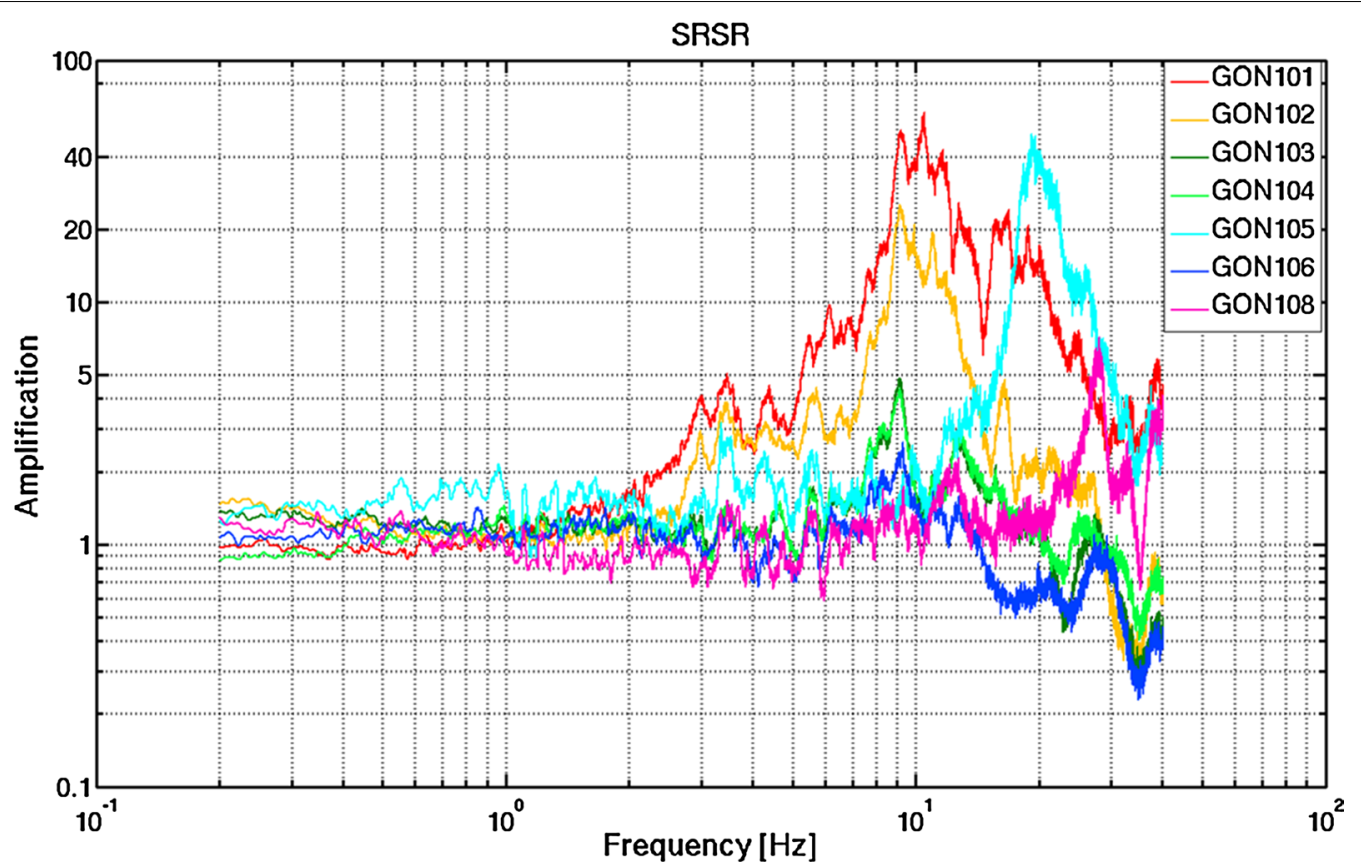

Fig. 8 SRSR of the measurement in June 2015 in the direction $40^{\circ}$ from north

Such extreme amplifications will likely to increase the transient strains during strong ground shaking, i.e., increasing the susceptibility of slopes to earthquake triggering. Although the resonant frequency of $10 \mathrm{~Hz}$ is relatively high, compared to corner frequencies of large and moderate earthquakes, strong accelerations might be expected even for weak and moderate earthquakes. Even if the slope does not collapse due to such strong high-frequency motions, it might be further weakened (Gischig et al. 2015).

The directions of maximum amplification are perpendicular to open cracks and are in good agreement with the deformation directions obtained by deformation measurements. Surface geometry alone does not explain high amplification and polarization at sites with pronounced topography (Burjánek et al. 2014). Based on our experience of around 25 investigated unstable slopes, directionality is typically linked to open cracks (Burjánek et al. 2012, 2017). Nevertheless, an apparent link to the free face of steep slopes is usually found for fractured sites as well, since the fractures played a role in the formation of the free face.

It would be very beneficial to install a permanent station in the area of the blue circle (in Fig. 7) in order to monitor the slope behavior in the future. Especially in case of complete or partial failure of the instable section A2, one could observe whether the seismic response is changing due to rock failure and the related mass release.

\section{Abbreviations}

SRSR: site-to-reference spectral ratios; TFPA: time-frequency-dependent polarization analysis; ASTRA: Swiss Federal Road Office; SBB: Swiss Federal Railways.

\section{Authors' contributions}

UK is involved in writing, estimating and interpreting the data. JB is involved in providing the scripts for polarization analysis and SRSR and helping with the data interpretation. DF is involved in helping with data interpretation. All authors read and approved the final manuscript.

\section{Author details}

${ }^{1}$ Swiss Seismological Service, ETH Zürich, Zurich, Switzerland. ${ }^{2}$ Institute of Geophysics of CAS, v.vi.., Prague, Czech Republic.

\section{Acknowledgements}

This study is funded by ETH Zürich under Research Grant ETH-1212-2. We would like to thank Urban Rieder (ASTRA), Meinrad Bittel (Roccaval) and Eric Pointner (Rovina + Partner AG) for supporting us with the site selection, helping in the field, respectively, providing mountain guides for the field work as well as providing additional information about the investigated sites.

\section{Competing interests}

The authors declare that they have no competing interests.

\section{Availability of data and materials}

The data analyzed in this paper were gathered in the frame work of a Ph.D. project funded by ETH. The data are stored at the Swiss Seismological Service and are available by request. Contact: Donat Fäh (donat.faeh@sed.ethz.ch).

\section{Funding}

ETH Zürich, Research Grant ETH-1212-2.

\section{Publisher's Note}

Springer Nature remains neutral with regard to jurisdictional claims in published maps and institutional affiliations. 
Received: 28 February 2017 Accepted: 31 August 2017

Published online: 11 September 2017

\section{References}

Arakawa T, Yamamoto K (2004) Frequencies and damping ratios of a high rise building based on microtremor measurement. In: Proceedings of 13th world conference on earthquake engineering, Vancouver, BC, Canada, Paper No. 48

ASTRA (Swiss Federal Road Office) (2012) Naturgefahren auf Nationalstrassen (Nationalstrasse N09), Los 13, Simplon; Beilage 2.6-Gefahrenbeurteilung-Prozess Sturz, GéoVal SA

ASTRA (Swiss Federal Road Office) (2014) Überwachung Felsinstabilitäten Galerie Alpjen Ost, Simplonstrasse, Zwischbergen, Messbericht Automatische Überwachung

Bottelin P, Jongmans D, Baillet L, Lebourg T, Hantz D, Lévy C, Le Roux O, Cadet H, Lorier L, Rouiller J-D, Turpin J, Darras L (2013) Spectral analysis of prone-to-fall rock compartments using ambient vibrations. J Environ Eng Geophys 18:205-217

Burjánek J, Gassner-Stamm G, Poggi V, Moore JR, Fäh D (2010) Ambient vibration analysis of an unstable mountain slope. Geophys J Int 180(2):820-828
Burjánek J, Moore JR, Yugsi Molina FX, Fäh D (2012) Instrumental evidence of normal mode rock slope vibration. Geophys J Int 188:559-569

Burjánek J, Edwards B, Fäh D (2014) Empirical evidence of local seismic effects at sites with pronounced topography: a systematic approach. Geophys J Int 197(1):608-619

Burjánek J, Gischig V, Moore JR, Fäh D (2017) Ambient vibration characterization and monitoring of a rock slope close to collapse. Geophys J Int (under revision)

Del Gaudio V, Muscillo S, Wasowski J (2014) What we can learn about slope response to earthquakes from ambient noise analysis: an overview. Eng Geol 182:182-200

Fäh D, Moore JR, Burjánek J, losifescu I, Dalguer LA, Dupray F, Michel C, Woessner J, Villiger A, Laue J et al (2012) Coupled seismogenic geohazards in Alpine region. Boll Geofis Teor Appl 53:485-508. doi:10.4430/bgta0048

Gischig V, Preisig G, Eberhardt E (2015) Numerical investigation of seismically induced rock mass fatigue as a mechanism contributing to the progressive failure of deep-seated landslides. Rock Mech Rock Eng 49:2457-2478

Kleinbrod U, Burjánek J, Fäh D (2017) From ambient vibration assessment of potential rock slope instabilities to earthquake triggered rockslides. In: 16th World conference on earthquake engineering, 16WCEE 2017, Paper No. 2216

Prieto GA, Parker RL, Vernon FL (2009) A Fortran 90 library for multitaper spectrum analysis. Comput Geosci 35:1701-1710

\section{Submit your manuscript to a SpringerOpen ${ }^{\circ}$ journal and benefit from:}

- Convenient online submission

- Rigorous peer review

- Open access: articles freely available online

- High visibility within the field

- Retaining the copyright to your article

Submit your next manuscript at $\boldsymbol{\nabla}$ springeropen.com 